\title{
BMI and cardiovascular function in children and adolescents of Mauritius Island
}

\author{
Jennifer L. Miles-Chan ${ }^{1}$, Noorjehan Joonas ${ }^{2}$, Shashee Joganah ${ }^{2}$, Jose Larhubarbe ${ }^{2}$, Yves Schutz ${ }^{3}$, \\ Jean-Pierre Montani ${ }^{1}$ and Abdul G. Dulloo ${ }^{1 *}$ \\ ${ }^{1}$ Department of Medicine/Physiology, University of Fribourg, Switzerland \\ ${ }^{2}$ Ministry of Health and Quality of Life, Mauritius \\ ${ }^{3}$ Faculty of Medicine and Biology, University of Lausanne, Switzerland
}

(Received 2 May 2012 - Final revision received 12 October 2012 - Accepted 15 October 2012)

Journal of Nutritional Science (2013), vol. 2, e3, page 1 of 8

doi:10.1017/jns.2012.26

Abstract

Among countries which have undergone a rapid socio-economic and nutrition transition over the past few decades, the Indian Ocean island of Mauritius is among those with the greatest surge in the prevalence of type 2 diabetes and CVD. The aim of the present study was to characterise the BMI and cardiovascular functions of children and adolescents of this at-risk population. Data were collected through measurements of anthropometry, resting heart rate and blood pressure in a nationally representative sample ( $n$ 2489) of children (5-10 years) and adolescents (11-18 years), and analysed according to sex and ethnic identity: South Asian Hindus and Muslims (both of Indian ancestry), Creole (of varying degrees of African ancestry) and Chinese (of mainland China ancestry). Based on standards of the WHO or International Obesity Task Force, one in six of these young individuals exhibit a high BMI-for-age. Analysis by ethnicity revealed that Creole males and females show higher BMI-for-age but also lower heart rate $(P<0 \cdot 001)$ even after adjustment for BMI. Additionally, Chinese males and females show higher systolic blood pressure $(P<0 \cdot 01)$, independently of BMI. None of these ethnic differences could be related to household income, diet type (vegetarian $v$. non-vegetarian) or to fruit consumption. This study in children and adolescents of this multi-ethnic at-risk population for CVD reveal ethnic differences in BMI-for-age as well as consistent BMI-independent ethnic differences in heart rate and systolic blood pressure. These findings underscore the need to establish the BMI-fat \% relationship across the various ethnic groups and for more detailed investigations about their differences in lifestyle and dietary habits that might explain their differential cardiovascular functions prior to adulthood.

Key words: Ethnicity: Obesity: Hypertension: Indian ancestry: Chinese ancestry: African ancestry

Since gaining independence in 1968, the island nation of Mauritius has experienced rapid economic growth, concomitant with a marked improvement in public health. Indeed, since 1960, life expectancy at birth has increased from 60 to 73 years, and the infant mortality rate has dropped from seventy to fourteen per 1000 live births ${ }^{(1)}$. However, the Mauritian population has not emerged from this rapid transition unscathed. The population now faces the health burdens of nutritional transition, with non-communicable diseases, in particular CVD and diabetes, currently the primary cause of morbidity and mortality. With the prevalence of adult type 2 diabetes, a main contributor to CVD, almost three times the predicted global prevalence ${ }^{(2)}$, the public health and subsequent economic impact is immense. A number of large population health surveys have been carried out on the island ${ }^{(3,4)}$, with the 1998 National Non-communicable Diseases Survey showing a prevalence of overweight (OW) and obesity of approximately 36 and $44 \%$ within the adult male and female population, respectively. However, despite decades of data collection and analysis concerning the adult population, the

Abbreviations: OW, overweight; SA, South Asian; UW, underweight.

* Corresponding author: A. G. Dulloo, fax +41263009734, email abdul.dulloo@unifr.ch

(C) The Author(s) 2013. The online version of this article is published within an Open Access environment subject to the conditions of the Creative Commons Attribution-NonCommercial-ShareAlike licence <http://creativecommons.org/licenses/by-nc-sa/2.5/>. The written permission of 
distribution of BMI and cardiovascular risk factors across a nationally representative sample of school-aged children and adolescents remains unreported. Furthermore, the 1.3 million Mauritians who inhabit the island are a multi-ethnic population, with the major ethnic groups being of South Asian (SA) Indian ancestry (52\% Hindu and $16 \%$ Muslim), varying degrees of African ancestry (Creoles $27 \%$ ), and Chinese ancestry (3\%). Given a plethora of recent research that suggests that individuals of Asian descent are at increased risk of type 2 diabetes and hypertension at lower $\mathrm{BMI}^{(5,6)}$, it therefore begs the question as to whether or not ethnic disparities in BMI and cardiovascular risk factors across these younger age groups exist. Therefore, the aim of the present study was (i) to characterise BMI and cardiovascular function (heart rate and blood pressure) in children and adolescents of this multi-ethnic 'at-risk' population, (ii) to determine the presence of any ethnic differences in these parameters and (iii) to investigate any potential link with general health and diet or socio-economic status.

\section{Methods}

\section{Study design}

The study design consisted of a cross-sectional, communitybased survey of a qualitative and quantitative nature.

The sampling method employed ensured a nationally representative sample, with sufficient numbers of subjects in each of the two target populations: 5-10 years of age (primary school-aged children) and 11-18 years of age (referred to as adolescents), and with the distribution of ethnicity being close to that of the whole Mauritian population. Subjects were selected from the fourteen Primary Enumeration Areas which were identified and chosen, under the guidance of the WHO Regional Office for Africa, for a non-communicable disease and risk factor survey that was being carried out simultaneously. This standardised non-communicable disease survey procedure has been described in detail elsewhere ${ }^{(7)}$. A random multi-stage cluster sampling procedure was applied to identify these fourteen clusters out of the 379 Primary Enumeration Areas defined by the Central Statistics Office and used in the island's 2000 population census. Between 161 and 207 individuals from each cluster were included in the final data analysis. This study was conducted according to the guidelines laid down in the Declaration of Helsinki and all procedures involving human subjects were approved by the ethics committee of the Mauritius Ministry of Health and Quality of Life. Written informed consent was obtained from all subjects or their parents.

\section{Data collection}

The field work was carried out between September and October 2004, with an overall response rate of 89.8 and $86.0 \%$ for the 5-10 years and 11-18 years groups, respectively. Data were collected by trained staff through interviews, anthropometric measurements and blood analysis. Ethnicity was determined by self-report to the interviewer. Monthly family income (used as a marker of socio-economic status) was classified as 'Rs. 8000 or less', or 'over Rs. 8000'. Diet type was defined as either 'vegetarian' (no animal flesh eaten) or 'non-vegetarian', and daily fruit consumption grouped into 'less than 2 per d' or ' 2 or more per d'. For all anthropometric measures, subjects wore light clothing and no shoes.

Body weight was measured to the nearest $0.1 \mathrm{~kg}$ without shoes and in light clothing, using a standard lever balance (Detecto). Two initial measurements were obtained, and if these varied by more than $0.5 \mathrm{~kg}$, a third measurement was taken. The mean of the two closest measurements was used for analysis. Scales used were calibrated daily.

Standing height was measured to the nearest $0.5 \mathrm{~cm}$ using a wall-mounted stadiometer (Seca 206). If the two initial measurements varied by more than $0.5 \mathrm{~cm}$, a third measurement was taken. The mean of the two closest measurements was used for analysis.

Heart rate and blood pressure measurements were performed in a seated position after a period of rest of at least 5 min, using a suitable cuff size and standard automated sphygmomanometer (Microlife). Two measurements were taken, with a 1 min interval between them, and the mean of the two measurements calculated. If the difference between the first and second measurement was greater than 10 $\mathrm{mmHg}$, for either systolic or diastolic blood pressure, a third measurement was taken, and the mean was calculated from the two closest readings.

Blood was collected by venepuncture in the non-fasting, random state. The subject was in the seated position and the sample was taken by the standard technique from the cubital fossa of the opposite arm to that used for the blood pressure measurement. A total of $10 \mathrm{ml}$ of whole blood was taken for anaemia profiling and for detecting infection, specifically through the measurements of blood $\mathrm{Hb}$, haematocrit, erythrocyte count and leucocyte count, in order to determine the overall health status and to take into account individuals displaying overt pathogenesis in the interpretation of data on $\mathrm{BMI}$ and cardiovascular function.

\section{Statistical analyses}

BMI-for-age was classified according to two different international standards: the $\mathrm{WHO}^{(8-10)}$ and the International Obesity Task Force ${ }^{(11,12)}$. Height-for-age was calculated using WHO growth references ${ }^{(13)}$. Differences in the tested variables (e.g. blood pressure) between categorical groups (e.g. ethnic, BMI-for-age classification, dietary and income groups) were assessed by ANOVA and subsequent Fisher's protected least-significant difference post hoc analysis. The effects of sex and age on these variables were tested by ANCOVA. Relationships between continuous variables (e.g. blood pressure, BMI-for-age $z$-score, height-for-age $z$-score and blood measurements) were assessed by regression analysis. Individuals aged 5-10 years were referred to as children and those aged 11-18 years as adolescents. All statistical tests were performed using Statview software (SAS Institute), with $P<0.05$ considered statistically significant. Unless otherwise stated, all data are presented as means with their standard errors. 


\section{Results}

\section{Characteristics of study population}

The present study consisted of 2489 individuals, with $48.5 \%$ male and $51.5 \%$ female. These individuals were further divided into subgroups based on age and ethnicity. The number of subjects in each subgroup is given in Table 1.

\section{$B M I$}

BMI-for-age $z$-scores of the Mauritian study population showed a marked left shift when compared with the WHO reference standards (Fig. 1). This shift, of 1 sD, occurs in both sexes and is independent of ethnicity.

After comparison using the WHO reference range (Table 2), the prevalence of low BMI-for-age (underweight; UW) was 13.6\%. However, UW or 'thinness', as defined by the International Obesity Task Force, was found in $31.5 \%$ of the study population; $19 \%$ 'thinness grade 1', $8.4 \%$ 'thinness grade 2', and $4.1 \%$ 'thinness grade 3'. Conversely, a high BMI-for-age (OW and obese) was observed in $18.5 \%$ (WHO) and $15.6 \%$ (International Obesity Task Force) of the study population.

BMI-for-age, classified by the WHO reference ranges, for each ethnic group is summarised in Table 3. Although the prevalence of high BMI-for-age (OW and obese) in the Creole population was not higher than in the other ethnic groups, the BMI-for-age distribution of the Creoles was found to be shifted to the right in the range of $z$-score corresponding to UW and normal weight ( $z$-score $<1$, Fig. 1$)$ when compared with both the SA Hindu $(P<0.001)$ and SA Muslim $(P<0 \cdot 05)$ groups, this difference being observed independently of age group and sex.

In those who responded to income/diet questioning, BMI-for-age showed no relationship to monthly family income ( $n$ 1318; ANOVA $P=0.96$ ), diet type ( $n$ 2482; ANOVA $P=0 \cdot 81$ ), or daily fruit consumption ( $n$ 2368; ANOVA $P=0 \cdot 65)$.

\section{Cardiovascular haemodynamics}

Heart rate showed a U-shaped relationship with the WHO BMI-for-age classification (Table 4), with higher heart rates

Table 1. Distribution of subjects ( $n$ 2489) by sex, age and ethnicity*

\begin{tabular}{|c|c|c|c|c|c|c|}
\hline & \multicolumn{2}{|c|}{ Male } & \multicolumn{2}{|c|}{ Female } & \multirow{2}{*}{$\begin{array}{c}\text { Male: } \\
\text { female } \\
\text { ratio }\end{array}$} & \multirow[b]{2}{*}{ Total } \\
\hline & Children & ADO & Children & ADO & & \\
\hline $\begin{array}{l}\text { South Asian } \\
\text { Hindu }\end{array}$ & 282 & 323 & 256 & 369 & 0.97 & 1230 \\
\hline $\begin{array}{l}\text { South Asian } \\
\text { Muslim }\end{array}$ & 147 & 195 & 164 & 172 & 1.02 & 678 \\
\hline Creole & 105 & 124 & 131 & 155 & 0.80 & 515 \\
\hline Chinese & 8 & 24 & 12 & 22 & 0.94 & 66 \\
\hline \multirow[t]{2}{*}{ Total } & 542 & 666 & 563 & 718 & 0.94 & 2489 \\
\hline & \multicolumn{2}{|c|}{1208} & \multicolumn{2}{|c|}{1281} & & \\
\hline
\end{tabular}

ADO, adolescents.

* Children, age 5-10 years; ADO, age 11-18 years. observed in the UW and obese groups $(P<0 \cdot 01)$ than in the normal-weight and OW groups.

Positive relationships were observed between WHO BMI-for-age classification and systolic $(P<0 \cdot 001)$, diastolic $(P<0.001)$, and subsequently pulse pressure $(P<0.001)$ (Table 4).

No relationships were found between any of the measured cardiovascular parameters and monthly family income, daily fruit consumption or diet type - with the exception of a slightly lower pulse pressure observed in the vegetarian $v$. the non-vegetarian group (vegetarian: 42 (SE 1.0) $\mathrm{mmHg}$; nonvegetarian 44 (SE 0.2) mmHg; ANOVA $P=0 \cdot 046$ ).

Creoles exhibited a significantly lower heart rate than both SA Hindus $(P<0.001)$ and SA Muslims $(P<0.001)$, irrespective of BMI-for-age (Table 5). This difference (approximately 3-4 beats per min) persists across age groups and sex.

The Chinese ethnic group showed a significantly elevated systolic blood pressure in comparison with all other ethnic groups (approximately $5.5 \mathrm{mmHg}, P<0 \cdot 01$; Table 5). This difference persists across sex and age groups, and is independent of BMI-for-age; no such difference was observed in diastolic blood pressure (Table 5).

Although height-for-age was positively correlated with both systolic and diastolic blood pressure across the population sample $(r 0.29 ; P<0.001)$, there was, however, no significant difference in height-for-age between ethnic groups (ANOVA $P=0 \cdot 7$ ), and furthermore, the elevated blood pressure observed in the Chinese group persisted when height-for-age was included as a covariate.

Similarly, the Chinese had significantly elevated pulse pressure in comparison with all other ethnicities (Creole, $P<0.05 ;$ SA Hindu, $P<0.001 ;$ SA Muslim, $P<0.01$; Table 5). However, despite being an independent cardiovascular risk factor, this difference in pulse pressure was solely due to the increased systolic blood pressure observed in this group.

\section{Blood markers}

Blood markers of anaemia and infections (blood Hb, haematocrit, erythrocyte count and leucocyte count) were measured during the present study in order to assess overall health status and ensure that observed changes in BMI and cardiovascular function were not related to overt pathogenesis. All these blood markers were within the internationally acceptable range.

From the blood sample analysis, the prevalence of anaemia (as defined by the WHO using blood $\mathrm{Hb}$ levels ${ }^{(15)}$ ) was found to be $7.1 \%$ overall $(4.3 \%$ in males; $9.7 \%$ in females). Of those anaemic individuals, twenty/120 females, and four/ forty-seven males presented with moderate anaemia, comprising just $1 \%$ of the overall study population, while the remainder were classified as mildly anaemic. This prevalence constitutes 'mild' public health significance by WHO standards. The overall prevalence of anaemia by Centers for Disease Control classification was $4.6 \%$ (4.9\% in females; $4.2 \%$ in males).

Despite a prevalence of $10.5 \%$ in the UW female sub-group, anaemia showed no statistical relationship with BMI-for-age classification $(P=0.93)$. The prevalence of anaemia in the UW group $(7.9 \%)$ was similar to that in the normal-weight 

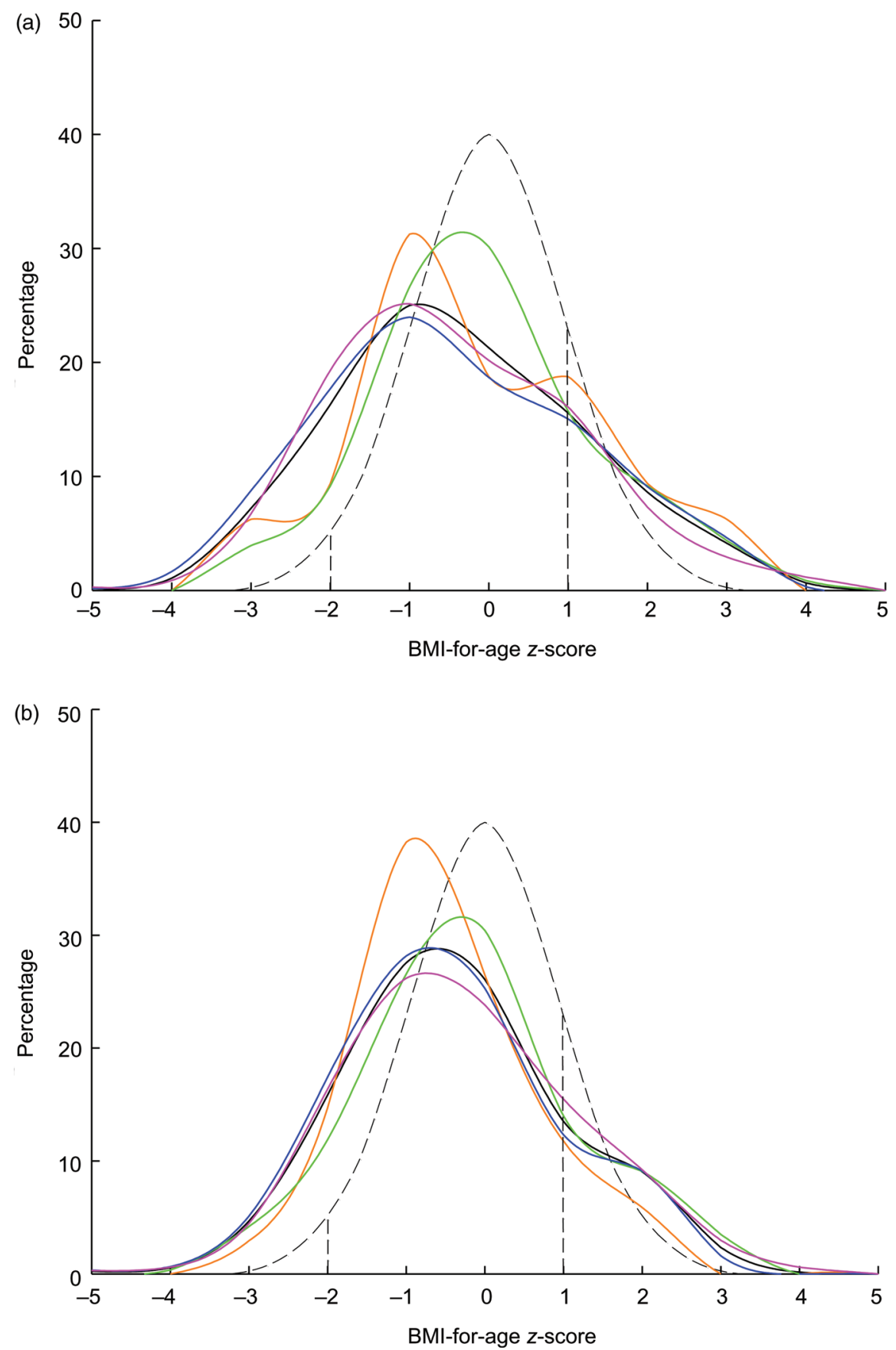

Fig. 1. BMI-for-age for (a) males and (b) females of each ethnic group in comparison with WHO standards ${ }^{(8,10,14)}$. — _ All ethnicities (1208 males, 1281 females); ---, WHO reference; — C Chinese (thirty-two males, thirty-four females); — - Creole (229 males, 286 females); — , South Asian Hindu (605 males, 625 females); _, South Asian Muslim (342 males, 336 females).

group $(7 \cdot 2 \%)$. However, positive correlations were observed between BMI (unadjusted for age) and blood $\mathrm{Hb}$ levels $(r 0 \cdot 21$; $P<0 \cdot 001)$, haematocrit levels $(r 0 \cdot 23 ; P<0 \cdot 001)$, and erythrocyte count $(r 0 \cdot 16 ; P<0 \cdot 001)$. Blood haematocrit and erythrocyte counts were higher in both the obese and OW groups compared with the normal-weight and UW groups, but all group averages were within the established reference ranges ${ }^{(16,17)}$.

Leucocyte count $(1000$ cells $/ \mu \mathrm{l})$ was significantly affected by ethnicity $(P<0.0001)$, with all four ethnic groups differing from one another - in increasing order: Chinese $(6 \cdot 18)$, Creole (6.87), SA Hindu (7.27), and SA Muslim (7.62). These differences persisted across age group and sex.
Conversely, the Chinese group presented higher blood $\mathrm{Hb}$ and haematocrit levels than all other ethnic groups. However, average values of these blood markers for each ethnicity were still within the Third National Health and Nutrition Examination Survey (NHANES III) reference ranges ${ }^{(16)}$.

\section{Discussion}

In the past four decades, the island of Mauritius has undergone rapid socio-economic development. However, despite vast improvements in public health, the Mauritian population has been experiencing a parallel increase in lifestyle-related 
Table 2. Comparison of the prevalence of underweight (UW), normal weight (NW), overweight (OW), and obese (OB) in the Mauritian population as defined by the $\mathrm{WHO}^{(8,10,14)}$ and International Obesity Task Force $(\mathrm{IOTF})^{(11,12)}$ standards, and stratified by age and sex ${ }^{*}$

\begin{tabular}{|c|c|c|c|c|c|c|c|c|c|c|}
\hline & \multicolumn{4}{|c|}{ Male } & \multicolumn{4}{|c|}{ Female } & & \\
\hline & \multicolumn{2}{|c|}{ Children } & \multicolumn{2}{|c|}{ ADO } & \multicolumn{2}{|c|}{ Children } & \multicolumn{2}{|c|}{ ADO } & \multicolumn{2}{|c|}{ Total } \\
\hline & $n$ & $\%$ & $n$ & $\%$ & $n$ & $\%$ & $n$ & $\%$ & $n$ & $\%$ \\
\hline \multicolumn{11}{|l|}{ WHO } \\
\hline UW & 100 & 18.5 & 76 & 13.7 & 91 & 13.5 & 72 & $10 \cdot 0$ & 339 & 13.6 \\
\hline NW & 349 & 64.4 & 425 & 63.8 & 389 & 69.1 & 527 & 73.4 & 1690 & 67.9 \\
\hline OW & 45 & 8.3 & 89 & 13.4 & 55 & $9 \cdot 8$ & 78 & $10 \cdot 9$ & 267 & $10 \cdot 7$ \\
\hline OB & 48 & 8.9 & 61 & 9.2 & 43 & $7 \cdot 6$ & 41 & $5 \cdot 7$ & 193 & $7 \cdot 8$ \\
\hline \multicolumn{11}{|l|}{ IOTF } \\
\hline UW & 211 & 38.9 & 171 & $25 \cdot 7$ & 199 & $35 \cdot 3$ & 203 & 28.3 & 784 & 31.5 \\
\hline NW & 265 & 48.9 & 364 & 54.7 & 279 & $49 \cdot 6$ & 409 & 57.0 & 1317 & 52.9 \\
\hline OW & 42 & 7.7 & 93 & 14.0 & 63 & 11.2 & 73 & $10 \cdot 2$ & 271 & $10 \cdot 9$ \\
\hline OB & 24 & 4.4 & 38 & 5.7 & 22 & 3.9 & 33 & 4.6 & 117 & 4.7 \\
\hline Total & 542 & & 666 & & 563 & & 542 & & 2489 & \\
\hline
\end{tabular}

ADO, adolescents.

* Children, age 5-10 years; ADO, age 11-18 years.

diseases, such as hypertension and type 2 diabetes. Although the prevalence of such conditions in the adult population is recognised and widely reported ${ }^{(3,4,18)}$, the cardiovascular health of the child and adolescent populations has thus far remained unknown.

The present study is the first to report the prevalence of OW/obesity and UW in both Mauritian school-aged children and adolescents. Interestingly, with approximately $17 \%$ of these individuals exhibiting a high BMI-for-age according to internationally recognised standards, and $32 \%$ having a low BMI-for-age, the results of this study highlight the 'double burden' commonly observed in newly developed and developing countries ${ }^{(19)}$. Indeed, these values are almost identical to those reported in Iranian children ${ }^{(20)}$ and exhibit a similar pattern those of the Seychelles ${ }^{(21)}$. These data are also in agreement with a recently published report of BMI among 9- to 10-year-old Mauritius children ${ }^{(22)}$, and a small-scale study investigating secondary school children in Mauritius in $2008^{(23)}$, perhaps indicating a relative stability in BMI distribution which merits large-scale follow-up investigation. Nonetheless, there was no indication that the relatively high prevalence of UW was associated with anaemia, as the prevalence of anaemia within the population was not noticeably elevated, and there was no observed relationship with BMI-for-age classification. Furthermore, in contrast to a recent small-scale study by Fokeena and Jeewon ${ }^{(24)}$, no relationship between BMI and socio-economic status (as measured by monthly family income) was observed, or any relation to diet type or daily fruit consumption.

It is important to remember, however, that BMI-for-age may not necessarily be reflective of body fat mass ${ }^{(25,26)}$. This is particularly pertinent when comparing between different ethnic groups. A number of studies have now demonstrated that the relationship between BMI and body fat mass differs across ethnic groups, with individuals of Asian descent, particularly those from the Indian sub-continent, shown to have a higher body fat mass, irrespective of $\mathrm{BMI}^{(27-29)}$. This observation has recently been confirmed in Australian children of

Table 3. Comparison of the prevalence of underweight (UW), normal weight (NW), overweight (OW) and obese (OB) in the Mauritian population as defined by $\mathrm{WHO}^{(8,10,14)}$ standards, and stratified by sex and ethnicity ${ }^{\star}$

\begin{tabular}{|c|c|c|c|c|c|c|c|c|c|}
\hline & \multicolumn{8}{|c|}{ WHO classification } & \multirow{3}{*}{$\frac{\text { Total }}{n}$} \\
\hline & \multicolumn{2}{|c|}{ UW } & \multicolumn{2}{|c|}{ NW } & \multicolumn{2}{|c|}{ OW } & \multicolumn{2}{|c|}{ OB } & \\
\hline & $n$ & $\%$ & $n$ & $\%$ & $n$ & $\%$ & $n$ & $\%$ & \\
\hline \multicolumn{10}{|l|}{ Male } \\
\hline South Asian Hindu & 113 & 18.7 & 370 & $61 \cdot 2$ & 66 & $10 \cdot 9$ & 56 & $9 \cdot 3$ & 605 \\
\hline South Asian Muslim & 54 & $15 \cdot 8$ & 222 & 64.9 & 35 & $10 \cdot 2$ & 31 & $9 \cdot 1$ & 342 \\
\hline Creole & 20 & 8.7 & 164 & 71.6 & 25 & $10 \cdot 9$ & 20 & 8.7 & 229 \\
\hline Chinese & 4 & $12 \cdot 5$ & 18 & $56 \cdot 3$ & 8 & $25 \cdot 0$ & 2 & $6 \cdot 3$ & 32 \\
\hline \multicolumn{10}{|l|}{ Female } \\
\hline South Asian Hindu & 84 & 13.4 & 444 & 71.0 & 63 & $10 \cdot 1$ & 34 & 5.4 & 625 \\
\hline South Asian Muslim & 40 & 11.9 & 233 & $69 \cdot 3$ & 35 & $10 \cdot 4$ & 28 & 8.3 & 286 \\
\hline Creole & 21 & $7 \cdot 3$ & 211 & 73.8 & 32 & $11 \cdot 2$ & 22 & 7.7 & 336 \\
\hline Chinese & 3 & 8.8 & 28 & 82.4 & 3 & 8.8 & 0 & 0.0 & 34 \\
\hline Total & 339 & $13 \cdot 6$ & 1690 & 67.9 & 267 & $10 \cdot 7$ & 193 & 7.8 & 2489 \\
\hline
\end{tabular}

ADO, adolescents.

* Children, age 5-10 years; ADO, age 11-18 years. 
Table 4. Comparison of cardiovascular function measured at rest for underweight (UW), normal weight (NW), overweight (OW) and obese (OB) as defined by the $\mathrm{WHO}^{(8,10,14)}$

(Mean values with their standard errors)

\begin{tabular}{|c|c|c|c|c|c|c|c|c|}
\hline & \multicolumn{2}{|c|}{ Heart rate (beats/min) } & \multicolumn{2}{|c|}{$\begin{array}{c}\text { Systolic blood } \\
\text { pressure }(\mathrm{mmHg})\end{array}$} & \multicolumn{2}{|c|}{$\begin{array}{l}\text { Diastolic blood } \\
\text { pressure }(\mathrm{mmHg})\end{array}$} & \multicolumn{2}{|c|}{$\begin{array}{l}\text { Pulse pressure } \\
(\Delta \mathrm{mmHg})\end{array}$} \\
\hline & Mean & $\mathrm{SE}$ & Mean & $\mathrm{SE}$ & Mean & $\mathrm{SE}$ & Mean & SE \\
\hline UW & $86 \cdot 8^{a}$ & 0.8 & $103 \cdot 5^{a}$ & 0.6 & $61 \cdot 1^{\mathrm{a}}$ & 0.5 & $42 \cdot 4^{\mathrm{a}}$ & 0.5 \\
\hline NW & $84 \cdot 6^{b}$ & 0.3 & $107 \cdot 2^{\mathrm{b}}$ & 0.3 & $63.5^{b}$ & 0.2 & $43 \cdot 6^{\mathrm{b}}$ & 0.2 \\
\hline OW & $84 \cdot 1^{b}$ & 0.9 & $111 \cdot 3^{\mathrm{c}}$ & 0.7 & $67 \cdot 6^{c}$ & 0.5 & $43 \cdot 7^{a, b}$ & 0.6 \\
\hline OB & $87.0^{a}$ & 1.0 & $115 \cdot 7^{d}$ & 1.0 & $69.2^{d}$ & 0.7 & $46 \cdot 4^{\mathrm{C}}$ & 0.9 \\
\hline ANOVA $P$ & \multicolumn{2}{|c|}{$<0.01$} & \multicolumn{2}{|c|}{$<0.001$} & \multicolumn{2}{|c|}{$<0.001$} & \multicolumn{2}{|c|}{$<0.001$} \\
\hline
\end{tabular}

a,b,c,d Mean values within a column with unlike superscript letters were significantly different $(P<0.05$; pair-wise statistical comparison by Fisher's protected least-significant difference test after significant difference across ethnic groups indicated by ANOVA).

Sri Lankan origin ${ }^{(30)}$ and also in Asian Indian adolescents from Guadeloupe ${ }^{(31)}$. Conversely, individuals of African descent have been shown to have a lower body fat mass and higher lean body mass for a given $\mathrm{BMI}^{(32)}$. Therefore, the elevated BMI-for-age observed in the Creoles of the present study should be interpreted with caution. If their higher BMI were to represent an elevated lean body mass, coupled with the persistently lower heart rate also seen independently of BMI in this group, it may indicate enhanced fitness, and therefore decreased cardiovascular risk in comparison with individuals of other ethnicity. This hypothesis remains to be tested with measurements of body composition and fitness.

Despite a relatively small group size, the Chinese displayed a number of concerning cardiovascular risk factors. The higher systolic blood pressure is of particular interest as, although $n$ is small and the statistical results should be interpreted with caution, this increase was found across both age groups and sexes, and independent of BMI. Furthermore, in spite of the majority $(90 \%)$ of the Chinese group inhabiting urban areas, sub-group analysis of these urban clusters found the systolic blood pressure to be persistently higher in the Chinese group in comparison with all other urban ethnic groups. Similarly, higher blood pressure was unrelated to anaemia and/or infection as by judged $\mathrm{Hb}$, haematocrit and leucocyte counts. It is unusual to observe such a large $(5 \mathrm{mmHg})$ and consistent difference in such a tightly regulated physiological parameter. The higher systolic blood pressure in children and adolescents of Chinese ethnicity has particular clinical relevance given that the adult Chinese population in Mauritius ${ }^{(33)}$, and indeed in China itself ${ }^{(34)}$, has already been reported to be at an increased risk of hypertension and CVD. Furthermore, elevated blood pressure in childhood and adolescence, even within the normal blood pressure range, is a recognised predictor of hypertension in adulthood ${ }^{(35-37)}$, and hence the observation that risk factors present early during growth in this ethnic group warrants further investigation. Whether the young Chinese have a higher salt consumption than the other ethnic groups would be one interesting avenue for future research. Indeed, our findings that their higher blood pressure resides primarily in a higher systolic blood pressure are consistent with wellcontrolled longitudinal studies of experimental hypertension ${ }^{(38)}$ indicating that the slow development of salt-induced hypertension arises primarily from an increase in systolic, rather than diastolic, blood pressure.

There are three limitations in the present study which should be discussed. Firstly, the blood samples obtained during the present study were collected in the non-fasting state, and as such the interpretable measurement of blood glucose and lipids was not possible. Furthermore, complementary measures of waist and hip circumferences were not made. Given the high prevalence of type 2 diabetes in the Mauritian adult population such measurements in the younger population are of particular interest and should be incorporated in future surveys. Secondly, the sample size of the Chinese group is much smaller than each of the other ethnicities. However, the ethnic distribution of our sample was close to that of Mauritius as a whole; with the Chinese population on the Island and our Chinese sample size both comprising $3 \%$ of the total. Thirdly, the large-scale nature of this epidemiological study and the cultural sensitivities of this multi-ethnic population precluded the assessment of pubertal stage. It is therefore possible

Table 5. Ethnic differences in cardiovascular function measured at rest (Mean values with their standard errors)

\begin{tabular}{|c|c|c|c|c|c|c|c|c|}
\hline & \multicolumn{2}{|c|}{ Heart rate (beats/min) } & \multicolumn{2}{|c|}{$\begin{array}{c}\text { Systolic blood } \\
\text { pressure }(\mathrm{mmHg})\end{array}$} & \multicolumn{2}{|c|}{$\begin{array}{l}\text { Diastolic blood } \\
\text { pressure }(\mathrm{mmHg})\end{array}$} & \multicolumn{2}{|c|}{$\begin{array}{l}\text { Pulse pressure } \\
(\Delta \mathrm{mmHg})\end{array}$} \\
\hline & Mean & SE & Mean & SE & Mean & SE & Mean & SE \\
\hline South Asian Hindu & $85.4^{a}$ & 0.4 & $107.5^{a}$ & 0.4 & 64.4 & 0.3 & $43 \cdot 1^{\mathrm{a}}$ & 0.3 \\
\hline South Asian Muslim & $86 \cdot 5^{a}$ & 0.5 & $107 \cdot 4^{\mathrm{a}}$ & 0.5 & 63.4 & 0.3 & $44 \cdot 0^{\mathrm{a}, \mathrm{b}}$ & 0.4 \\
\hline Creole & $82 \cdot 3^{\mathrm{b}}$ & 0.6 & $108 \cdot 3^{\mathrm{a}}$ & 0.5 & 63.9 & 0.4 & $44.4^{b}$ & 0.4 \\
\hline Chinese & $84 \cdot 7^{\mathrm{a}, \mathrm{b}}$ & 1.6 & $113.2^{b}$ & 1.5 & 65.7 & 1.0 & $47.5^{\mathrm{C}}$ & 1.2 \\
\hline ANOVA $P$ & \multicolumn{2}{|c|}{$<0.001$} & \multicolumn{2}{|c|}{$<0.01$} & \multicolumn{2}{|c|}{ NS } & \multicolumn{2}{|c|}{$<0.001$} \\
\hline
\end{tabular}

${ }^{a, b, c}$ Mean values within a column with unlike superscript letters were significantly different $(P<0.05$; pair-wise statistical comparison by Fisher's protected least-significant difference test after significant difference across ethnic groups indicated by ANOVA). 
that some individuals within the younger age group (5-10 years) had already entered puberty, and conversely that some individuals in the older age group (11-18 years) were in the pre-pubertal stage. It could be argued that this may have confounded the results, particularly with respect to the Chinese sample, where the ratio of children to adolescents was different from that of the other ethnic groups. However, our conclusions of BMI-independent ethnic differences in cardiovascular function in the investigated population remain valid since the higher blood pressure in those of Chinese ethnicity as well as the lower heart rate and higher BMI in the Creoles were all observed across both age groups and across sex.

Childhood and adolescence are important phases of development, and represent significant targets for intervention and the prevention of adulthood diseases. Globally, industrialised and developing countries alike are experiencing rapidly increasing levels of adult obesity and associated CVD, with such pathophysiologies appearing in younger individuals with each passing generation. Indeed, the present study reveals ethnic differences in BMI-for-age as well as consistent, BMI-independent, ethnic differences in heart rate and systolic blood pressure. These findings highlight the early emergence of risk factors in a recognized at-risk population for CVD, and underscore the need to establish the BMI-fat percentage relationship across the various ethnic groups. Coupled with more detailed analyses of lifestyle and dietary habits which might explain this differential cardiovascular risk prior to adulthood, such research will enable us to accurately assess the current state of cardiovascular health across all age groups, sexes and ethnicities, and target research, education, and expenditure accordingly, to stem this burgeoning health crisis.

\section{Acknowledgements}

None of the authors has any conflict of interest to disclose. The authors' contributions were as follows: S. J. and J. L. were involved in the study planning and population sampling design; N. J. was responsible for the blood sample analysis; J. L. M.-C., J.-P. M., Y. S. and A. G. D. contributed to data analysis and interpretation. J. L. M.-C. wrote the initial draft of the manuscript, and J.-P. M., Y. S. and A. G. D. contributed towards its final version. All authors read and approved the final version. The authors would like to thank Mr Nasser Jeeanody (Ministry of Health, Mauritius) for his suggestions concerning various aspects of the manuscript, and acknowledge the large number of individuals (nurses, doctors and other staff of the Ministry of Health) involved in the design, implementation and conduct of the survey in Mauritius. This research received no specific grants from any funding agency in the public, commercial or not-for-profit sectors.

\section{References}

1. Devi S (2008) Mauritius counts health successes. Lancet 371, 1567-1568.

2. Shaw JE, Sicree RA \& Zimmet PZ (2010) Global estimates of the prevalence of diabetes for 2010 and 2030. Diabetes Res Clin Pract 87, 4-14.
3. Soderberg S, Zimmet P, Tuomilehto J, et al. (2005) Increasing prevalence of type 2 diabetes mellitus in all ethnic groups in Mauritius. Diabet Med 22, 61-68.

4. Magliano DJ, Soderberg S, Zimmet PZ, et al. (2010) Mortality, allcause and cardiovascular disease, over 15 years in multiethnic Mauritius: impact of diabetes and intermediate forms of glucose tolerance. Diabetes Care 33, 1983-1989.

5. Jafar TH, Chaturvedi N \& Pappas G (2006) Prevalence of overweight and obesity and their association with hypertension and diabetes mellitus in an Indo-Asian population. CMAJ 175, 1071-1077.

6. Razak F, Anand SS, Shannon H, et al. (2007) Defining obesity cut points in a multiethnic population. Circulation 115, 2111-2118.

7. Dowse GK, Gareeboo H, Zimmet PZ, et al. (1990) High prevalence of NIDDM and impaired glucose tolerance in Indian, Creole, and Chinese Mauritians. Mauritius Noncommunicable Disease Study Group. Diabetes 39, 390-396.

8. World Health Organization (2006) Department of Nutrition for Health and Development. WHO Child Growth Standards based on length/height, weight and age. Acta Paediatr Suppl 450, 76-85.

9. World Health Organization (2007) Growth reference data for 5-19 years. http://www.who.int/growthref/en/ (accessed 16 October 2010).

10. de Onis M, Onyango AW, Borghi E, et al. (2007) Development of a WHO growth reference for school-aged children and adolescents. Bull World Health Organ 85, 660-667.

11. Cole TJ, Bellizzi MC, Flegal KM, et al. (2000) Establishing a standard definition for child overweight and obesity worldwide: international survey. Br Med J 320, 1240-1243.

12. Cole TJ, Flegal KM, Nicholls D, et al. (2007) Body mass index cut offs to define thinness in children and adolescents: international survey. Br Med J 335, 194.

13. World Health Organization (2007) Growth reference 5-19 years: height-for-age $\mathrm{z}$-scores tables for boys and girls. http://www. who.int/growthref/who2007_height_for_age/en/index.html (accessed 17 August 2012).

14. World Health Organization (2007) Growth reference 5-19 years: BMI-for-age tables for girls and boys. http://www.who.int/ growthref/who2007_bmi_for_age/en/index.html (accessed 16 April 2010).

15. World Health Organization (2001) Iron Deficiency Anaemia: Assessment, Prevention and Control: A Guide for Programme Managers. p. 114. Geneva: World Health Organization.

16. Cheng CK, Chan J, Cembrowski GS, et al. (2004) Complete blood count reference interval diagrams derived from NHANES III: stratification by age, sex, and race. Lab Hematol 10, 42-53.

17. Centers for Disease Control (1989) CDC criteria for anemia in children and childbearing-aged women. MMWR Morb Mortal Wkly Rep 38, 400-404.

18. Nyamdorj R, Qiao Q, Soderberg S, et al. (2009) BMI compared with central obesity indicators as a predictor of diabetes incidence in Mauritius. Obesity (Silver Spring) 17, 342-348.

19. Ke-You G \& Da-Wei F (2001) The magnitude and trends of underand over-nutrition in Asian countries. Biomed Environ Sci 14, 53-60.

20. Motlagh ME, Kelishadi R, Amirkhani MA, et al. (2001) Double burden of nutritional disorders in young Iranian children: findings of a nationwide screening survey. Public Health Nutr 14, 605-610.

21. Bovet P, Chiolero A, Madeleine G, et al. (2010) Prevalence of overweight and underweight in public and private schools in the Seychelles. Int J Pediatr Obes 5, 274-278.

22. Caleyachetty R, Rudnicka AR, Echouffo-Tcheugui JB, et al. (2012) Prevalence of overweight, obesity and thinness in 9-10 year old children in Mauritius. Global Health 8, 28.

23. Shamachurn B, Goorah S \& Oogarah-Pratap B (2008) Prevalence of overweight and obesity in a cohort of secondary school children in Mauritius in 2008. In University of Mauritius Research Week, 1-5 September 2008, P5.

24. Fokeena WB \& Jeewon R (2012) Is there an association between socioeconomic status and body mass index among adolescents in Mauritius? Sci World J 2012, 750659. 
25. Okorodudu DO, Jumean MF, Montori VM, et al. (2010) Diagnostic performance of body mass index to identify obesity as defined by body adiposity: a systematic review and meta-analysis. Int $J$ Obes (Lond) 34, 791-799.

26. Dulloo AG, Jacquet J, Solinas G, et al. (2010) Body composition phenotypes in pathways to obesity and the metabolic syndrome. Int J Obes (Lond) 34, Suppl. 2, S4-S17.

27. Wang J, Thornton JC, Russell M, et al. (1994) Asians have lower body mass index (BMI) but higher percent body fat than do whites: comparisons of anthropometric measurements. Am J Clin Nutr 60, 23-28.

28. Swinburn BA, Craig PL, Daniel R, et al. (1996) Body composition differences between Polynesians and Caucasians assessed by bioelectrical impedance. Int J Obes Relat Metab Disord 20, 889-894.

29. Gurrici S, Hartriyanti Y, Hautvast JG, et al. (1999) Differences in the relationship between body fat and body mass index between two different Indonesian ethnic groups: the effect of body build. Eur J Clin Nutr 53, 468-472.

30. Wickramasinghe VP, Cleghorn GJ, Edmiston KA, et al. (2005) Impact of ethnicity upon body composition assessment in Sri Lankan Australian children. J Paediatr Child Health 41, 101-106.

31. Sinnapah S, Antoine-Jonville S \& Hue O (2009) Asian Indian adolescents from Guadeloupe are fatter than their island counterparts. Br J Nutr 102, 1820-1827.
32. Deurenberg P, Yap M \& van Staveren WA (1998) Body mass index and percent body fat: a meta analysis among different ethnic groups. Int J Obes Relat Metab Disord 22, 1164-1171.

33. Li N, Tuomilehto J, Dowse G, et al. (1992) Electrocardiographic abnormalities and associated factors in Chinese living in Beijing and in Mauritius. The Mauritius Non-Communicable Disease Study Group. Br Med J 304, 1596-1601.

34. Wang D, Li Y, Lee SG, et al. (2011) Ethnic differences in body composition and obesity related risk factors: study in Chinese and white males living in China. PLoS ONE 6, e19835.

35. Camhi SM \& Katzmarzyk PT (2010) Tracking of cardiometabolic risk factor clustering from childhood to adulthood. Int J Pediatr Obes 5, 122-129.

36. Williams CL, Hayman LL, Daniels SR, et al. (2002) Cardiovascular health in childhood: a statement for health professionals from the Committee on Atherosclerosis, Hypertension, and Obesity in the Young (AHOY) of the Council on Cardiovascular Disease in the Young, American Heart Association. Circulation 106, 143-160.

37. Tirosh A, Afek A, Rudich A, et al. (2010) Progression of normotensive adolescents to hypertensive adults: a study of 26,980 teenagers. Hypertension 56, 203-209.

38. Denton D, Weisinger R, Mundy NI, et al. (1995) The effect of increased salt intake on blood pressure of chimpanzees. Nature Med 1, 1009-1016. 